\title{
Calcium Channel Blockers for the Clinical Management of Hypertension
}

\author{
Massimo Volpe ${ }^{1,2}$ (1)
}

Received: 9 September 2017/Accepted: 22 September 2017/Published online: 11 October 2017

(C) Springer International Publishing AG 2017

Current European guidelines recommend to start antihypertensive therapy with either monotherapy in those individuals with grade 1 hypertension and low-to-moderate global cardiovascular risk profile, or with dual combination therapies in those patients with grade 2-3 hypertension or high-to-very-high global cardiovascular risk profile [1]. In both cases, physicians' choice regarding antihypertensive drug classes should be limited to the following ones: angiotensin converting enzyme (ACE) inhibitors, angiotensin receptor blockers (ARBs), calcium channel blockers (CCBs), beta-blockers (BBs) and diuretics, which are currently recommended as first-line therapy [1]. Although it is stated that there is a substantial equivalence among classes in terms of antihypertensive effectiveness and cardiovascular protection [2], there are also numerous studies demonstrating clinically relevant differences in terms of safety and tolerability [3-5], as well as effects on organ damage [6, 7] and metabolic abnormalities [8, 9]. In addition, several clinical studies and post hoc analyses from randomized clinical trials performed in hypertensive patients at different cardiovascular risk profile have consistently demonstrated favourable clinical properties of drugs inhibiting the renin-angiotensin system, i.e. ACE inhibitors and ARBs, and CCBs in terms of metabolic abnormalities and improved vascular function compared to

Massimo Volpe

massimo.volpe@uniroma1.it

1 Division of Cardiology, Department of Clinical and Molecular Medicine, Faculty of Medicine and Psychology, Sant'Andrea Hospital, University of Rome Sapienza, Rome, Italy

2 IRCCS Neuromed, Pozzilli, IS, Italy antihypertensive therapies based on either BBs or diuretics or both [10-12].

All these aspects should be taken into account when prescribing antihypertensive medications in patients with sustained high blood pressure levels, since treated uncontrolled hypertension is persistently responsible of the vast majority of the burden of cardiovascular diseases in various countries, including Italy [13]. In particular, one neglected aspect of the antihypertensive therapy is the consideration on tolerability profile, i.e. the potential risk of experiencing drug-related side effects or adverse reactions of a given antihypertensive strategy, both in monotherapy and in combination therapy. Several observational studies, in fact, reported that about half of treated hypertensive patients spontaneously interrupted prescribed medications after 1 year of treatment, and this was largely independent of the baseline blood pressure levels and the achievement of blood pressure control [10-12]. Yet, drug discontinuations are often related to safety or tolerability issues, beyond the clinical effectiveness of a specific antihypertensive therapy.

On the basis of these considerations, not only the choice of a preferred antihypertensive drug class, but also the selection of specific compounds within the same class of antihypertensive drugs may have potential clinical impact, in view of the different pharmacokinetic and pharmacodynamic properties, as well as the different tolerability profile among various compounds. As an example, within the class of CCBs, different formulations of nifedipine, one of the most commonly prescribed dihydropyridinic $\mathrm{CCB}$ for treating hypertension, may have potentially harmful side effects on heart rate when used in short-lasting formulation, whereas it may provide prolonged blood pressure lowering reductions when used in gastrointestinal therapeutic system. 
In this issue of High Blood Pressure \& Cardiovascular Prevention, a comprehensive overview of the beneficial effects of dihydropyridinic CCBs for the clinical management of hypertension and associated clinical conditions is provided [14]. This work originates from an educational program performed in Italy in 2016, and devoted to different professional figures involved in the clinical management of hypertension. The program, entitled THYPER evolution, was aimed at improving the clinical management of hypertension and ameliorating blood pressure control rates by adopting rational, effective and well-tolerated antihypertensive drug therapies, with a particular focus on the use of the CCB barnidipine.

Among others, some specific aspects of this review should be discussed. First of all, it has been highlighted that the available evidence support the use of CCBs as first-line strategy, both in monotherapy and in combination therapies, mostly in association with either ACE inhibitors or ARBs. Such approach has demonstrated to provide effective and sustained blood pressure reductions over the entire 24-h period in different categories of hypertensive patients, and, mostly, to ensure high level of safety and tolerability. In particular, barnidipine-based antihypertensive therapy has proven to be safe, effective and well tolerated, with a lower incidence of side effects (e.g. ankle oedema) [15-18]. These properties may allow lower rates of discontinuations and promote the achievement of higher rates of blood pressure control in treated hypertensive patients. Secondly, it has been also discussed the beneficial effects provided by barnidipine in terms of hypertension-related cardiac and vascular organ damage, which have been observed in hypertensive patients with left ventricular hypertrophy and impaired vascular function (i.e. endothelial dysfunction) [19-23]. Finally, the use of CCBs has demonstrated to significantly reduce the risk of major cardiovascular and cerebrovascular complications, thus reducing the burden of hypertension-related diseases [24-33].

In conclusion, the choice of $\mathrm{CCBs}$ can be considered a safe, effective and well-tolerated option for ameliorating the clinical outcomes in hypertensive patients at different risk profile. These drugs, in fact, have demonstrated to provide greater and more sustained blood pressure reductions compared to other drug classes of antihypertensive agents, both in monotherapies and in combination therapies. Within the CCB class, the choice of barnidipine may further promote the achievement of the recommended blood pressure targets in different categories of hypertensive patients, including elderly and high risk individuals, with a favourable metabolic profile and excellent tolerability.

\section{Compliance with Ethical Standards}

Funding Expert review of the manuscript has been founded by Sigma-Tau.

Conflict of Interest Disclosure Author has served in international advisory boards of Daiichi Sankyo, Menarini International, Amgen and Novartis, and has lectured in symposia supported by Guidotti and Malesci.

Ethical Approval This article does not contain data derived by any current studies with human participants performed by any of the authors. The clinical studies mentioned were provided with specific ethical approval.

\section{References}

1. Mancia G, Fagard R, Narkiewicz K, Redon J, Zanchetti A, Bohm M, et al. 2013 ESH/ESC Guidelines for the management of arterial hypertension: the Task Force for the management of arterial hypertension of the European Society of Hypertension (ESH) and of the European Society of Cardiology (ESC). J Hypertens. 2013;31(7):1281-357.

2. Ettehad D, Emdin CA, Kiran A, Anderson SG, Callender T, Emberson $\mathrm{J}$, et al. Blood pressure lowering for prevention of cardiovascular disease and death: a systematic review and metaanalysis. Lancet. 2016;387(10022):957-67.

3. Corrao G, Nicotra F, Parodi A, Zambon A, Heiman F, Merlino L, et al. Cardiovascular protection by initial and subsequent combination of antihypertensive drugs in daily life practice. Hypertension. 2011;58:566-72.

4. Corrao G, Parodi A, Zambon A, Heiman F, Filippi A, Cricelli C, et al. Reduced discontinuation of antihypertensive treatment by two-drug combination as first step. Evidence from daily life practice. J Hypertens. 2010;28(7):1584-90.

5. Corrao G, Zambon A, Parodi A, Poluzzi E, Baldi I, Merlino L, et al. Discontinuation of and changes in drug therapy for hypertension among newly-treated patients: a population-based study in Italy. J Hypertens. 2008;26(4):819-24.

6. Verdecchia P, Angeli F, Borgioni C, Gattobigio R, de Simone G, Devereux RB, et al. Changes in cardiovascular risk by reduction of left ventricular mass in hypertension: a meta-analysis. Am J Hypertens. 2003;16(11 Pt 1):895-9.

7. Schmieder RE, Martus P, Klingbeil A. Reversal of left ventricular hypertrophy in essential hypertension. A meta-analysis of randomized double-blind studies. JAMA. 1996;275(19):1507-13.

8. Haffner SM, Ruilope L, Dahlof B, Abadie E, Kupfer S, Zannad F. Metabolic syndrome, new onset diabetes, and new end points in cardiovascular trials. J Cardiovasc Pharmacol. 2006;47(3):469-75.

9. Messerli FH, Grossman E, Leonetti G. Antihypertensive therapy and new onset diabetes. J Hypertens. 2004;22(10):1845-7.

10. Volpe M, Brommer P, Haag U, Miele C. Efficacy and tolerability of olmesartan medoxomil combined with amlodipine in patients with moderate to severe hypertension after amlodipine monotherapy: a randomized, double-blind, parallel-group, multicentre study. Clin Drug Investig. 2009;29(1):11-25.

11. Weir MR, Punzi HA, Flack JM, Stoakes KA, Chavanu KJ, Li W, et al. A randomized, double-blind, forced-titration study to compare olmesartan medoxomil versus losartan potassium in patients with stage 1 and 2 hypertension. Postgrad Med. 2011;123(1):80-7. 
12. Weir MR, Hsueh WA, Nesbitt SD, Littlejohn TJ 3rd, Graff A, Shojaee A, et al. A titrate-to-goal study of switching patients uncontrolled on antihypertensive monotherapy to fixed-dose combinations of amlodipine and olmesartan medoxomil \pm hydrochlorothiazide. J Clin Hypertens (Greenwich). 2011;13(6):404-12.

13. Tocci G, Sciarretta S, Volpe M. Development of heart failure in recent hypertension trials. J Hypertens. 2008;26(7):1477-86.

14. Tocci G, et al. High Blood Press Cardiovasc Prev 2017 (in press)

15. Rossetti G, Pizzocri S, Brasca F, Pozzi M, Beltrami LM, Bolla $\mathrm{GB}$, et al. Antihypertensive effect of barnidipine $10 \mathrm{mg}$ or amlodipine 5 to $10 \mathrm{mg}$ once daily in treatment-naive patients with essential hypertension: a 24-week, randomized, open-label, pilot study. Curr Ther Res Clin Exp. 2008;69(3):192-206.

16. Parati G, Giglio A, Lonati L, Destro M, Ricci AR, Cagnoni F, et al. Effectiveness of barnidipine 10 or $20 \mathrm{mg}$ plus losartan 50-mg combination versus losartan 100-mg monotherapy in patients with essential hypertension not controlled by losartan 50-mg monotherapy: a 12-week, multicenter, randomized, openlabel, parallel-group study. Clin Ther. 2010;32(7):1270-84.

17. Lins R, Marckx P, Vandebeek R, Vanhoutvinck C, Neuville O. Barnidipine real-life tolerability in arterial hypertension: results from the BASIC-HT study. Acta Clin Belg. 2015;70(4):244-50.

18. Lins R, Haerden Y, de Vries C. Replacement of amlodipine and lercanidipine by barnidipine: tolerability and effectiveness in a real-life study. High Blood Press Cardiovasc Prev. 2017;24(1):29-36.

19. Angeli F, Repaci S, Borgioni C, Sardone M, Scotti A, Verdecchia P. Effects of barnidipine on blood pressure and left ventricular diastolic function in patients with hypertension and metabolic syndrome: a 12-week, open-label noncomparison study. Curr Thera Res Clin Exp. 2008;69(3):207-20.

20. Derosa G, Querci F, Franzetti I, Dario Ragonesi P, D’Angelo A, Maffioli P. Comparison of the effects of barnidipine + losartan compared with telmisartan + hydrochlorothiazide on several parameters of insulin sensitivity in patients with hypertension and type 2 diabetes mellitus. Hypertens Res. 2015;38(10):690-4.

21. Derosa G, Mugellini A, Querci F, Franzetti I, Pesce RM, D'Angelo A, et al. Barnidipine or lercanidipine on echocardiographic parameters in hypertensive, type 2 diabetics with left ventricular hypertrophy: a randomized clinical trial. Sci Rep. 2015;05(5):12603.

22. Derosa G, Mugellini A, Pesce RM, D'Angelo A, Maffioli P. Barnidipine compared to lercanidipine in addition to losartan on endothelial damage and oxidative stress parameters in patients with hypertension and type 2 diabetes mellitus. BMC Cardiovasc Disord. 2016;12(16):66.

23. Muiesan ML, Salvetti M, Belotti E, Paini A, Rosei CA, Aggiusti $\mathrm{C}$, et al. Effects of barnidipine in comparison with hydrochlorothiazide on endothelial function, as assessed by flow mediated vasodilatation in hypertensive patients. Blood Press. 2011;20(4):244-51.

24. Staessen JA, Fagard R, Thijs L, Celis H, Arabidze GG, Birkenhager $\mathrm{WH}$, et al. Randomised double-blind comparison of placebo and active treatment for older patients with isolated systolic hypertension. The Systolic Hypertension in Europe (Syst-Eur) Trial Investigators. Lancet. 1997;350(9080):757-64.

25. Hansson L, Lindholm LH, Ekbom T, Dahlof B, Lanke J, Schersten B, et al. Randomised trial of old and new antihypertensive drugs in elderly patients: cardiovascular mortality and morbidity the Swedish Trial in Old Patients with Hypertension-2 study. Lancet. 1999;354(9192):1751-6.

26. Brown MJ, Palmer CR, Castaigne A, de Leeuw PW, Mancia G, Rosenthal $\mathrm{T}$, et al. Morbidity and mortality in patients randomised to double-blind treatment with a long-acting calciumchannel blocker or diuretic in the International Nifedipine GITS study: intervention as a Goal in Hypertension Treatment (INSIGHT). Lancet. 2000;356(9227):366-72.

27. Malacco E, Mancia G, Rappelli A, Menotti A, Zuccaro MS, Coppini A. Treatment of isolated systolic hypertension: the SHELL study results. Blood Press. 2003;12(3):160-7.

28. Hansson L, Hedner T, Lund-Johansen P, Kjeldsen SE, Lindholm $\mathrm{LH}$, Syvertsen JO, et al. Randomised trial of effects of calcium antagonists compared with diuretics and beta-blockers on cardiovascular morbidity and mortality in hypertension: the Nordic Diltiazem (NORDIL) study. Lancet. 2000;356(9227):359-65.

29. Black HR, Elliott WJ, Grandits G, Grambsch P, Lucente T, White WB, et al. Principal results of the Controlled Onset Verapamil Investigation of Cardiovascular End Points (CONVINCE) trial. JAMA. 2003;289(16):2073-82.

30. Pepine CJ, Handberg EM, Cooper-DeHoff RM, Marks RG, Kowey $\mathrm{P}$, Messerli FH, et al. A calcium antagonist vs a noncalcium antagonist hypertension treatment strategy for patients with coronary artery disease. The International Verapamil-Trandolapril Study (INVEST): a randomized controlled trial. JAMA. 2003;290(21):2805-16.

31. Liu L, Zhang Y, Liu G, Li W, Zhang X, Zanchetti A. The Felodipine Event Reduction (FEVER) Study: a randomized longterm placebo-controlled trial in Chinese hypertensive patients. J Hypertens. 2005;23(12):2157-72.

32. Officers A, Coordinators for the ACRGTA, Lipid-Lowering Treatment to Prevent Heart Attack T. Major outcomes in highrisk hypertensive patients randomized to angiotensin-converting enzyme inhibitor or calcium channel blocker vs diuretic: the Antihypertensive and Lipid-Lowering Treatment to Prevent Heart Attack Trial (ALLHAT). JAMA. 2002;288(23):2981-97.

33. Jamerson K, Weber MA, Bakris GL, Dahlof B, Pitt B, Shi V, et al. Benazepril plus amlodipine or hydrochlorothiazide for hypertension in high-risk patients. $\mathrm{N}$ Engl $\mathrm{J}$ Med. 2008;359(23):2417-28. 